\title{
Enhancement of sediment suspension and nutrient flux by benthic macrophytes at low biomass
}

\author{
S. E. Lawson*, K. J. McGlathery, P. L. Wiberg \\ Department of Environmental Sciences, University of Virginia, 291 McCormick Rd., Charlottesville, Virginia 22904, USA
}

\begin{abstract}
In shallow coastal ecosystems where most of the seafloor typically lies within the photic zone, benthic autotrophs dominate primary production and mediate nutrient cycling and sediment stability. Because of their different structure and metabolic rates, the 2 functional groups of benthic macrophytes (seagrasses, macroalgae) have distinct influences on benthic-pelagic coupling. Most research to date in these soft-bottomed systems has focused on mature seagrass meadows where shoot densities are high and on dense macroalgal mats that accumulate in response to eutrophication. Relatively little is known about the influence of low-biomass stands of seagrass and macroalgae on nutrient fluxes and sediment suspension. Using an erosion microcosm with controlled forcing conditions, we tested the effects of the eelgrass Zostera marina L. and the invasive macroalga Gracilaria vermiculophylla on sediment suspension and nutrient fluxes under high-flow conditions. At low densities, G. vermiculophylla increased sediment suspension and increased the nutrient flux from the sediment to the water column. For macroalgae, increased sediment suspension is likely due to dislodgement of sediment particles by bedload transport of the algae. In this case, the increase in sediment transport was reflected in an increase in nutrient flux from the sediment, showing that modification of physical forcing by benthic primary producers can also affect nutrient flux. The presence or absence of $Z$. marina did not have a significant effect on nutrient flux. However, the results suggest that there may be a range of low shoot densities for which storm-like flows increase sediment suspension to values higher than those expected for a bare sediment bed.
\end{abstract}

KEY WORDS: Benthic macrophytes - Sediment suspension - Nutrient flux - Seagrass · Benthic-pelagic coupling $\cdot$ Coastal bay $\cdot$ Lagoon

Resale or republication not permitted without written consent of the publisher

\section{INTRODUCTION}

In shallow coastal ecosystems where the seafloor typically lies within the photic zone, benthic autotrophs dominate primary production and mediate nutrient cycling and sediment stability (SandJensen \& Borum 1991, McGlathery et al. 2007). The strong benthic-pelagic coupling in these systems is influenced by both the distinct structure and the metabolic rates of the 2 functional groups of benthic macrophytes, viz. seagrasses and macroalgae (McGlathery et al. 2007). Almost all studies on the effects of seagrasses and macroalgae have been conducted on mature or high-density beds (e.g. Gambi et al.
1990, Fonseca \& Cahalan 1992, Escartín \& Aubrey 1995, Sfriso et al. 2005). Compared to these highdensity populations, we know little about the effects of lower densities of benthic macrophytes on sediment and nutrient fluxes, even though it is common for seagrasses and macroalgae to occur at low densities. For example, multiple stressors, including sediment and nutrient runoff, algal blooms, and physical disturbances from storms, boat traffic, and some fishing practices, can cause thinning and/or patchiness in seagrass populations in addition to wholesale losses of seagrass habitat (Duarte 2002, Orth et al. 2006). Restoration of seagrass meadows, especially by seeding, also results initially in low-density populations 
that increase in density as the meadows develop over time (McGlathery et al. 2012, Orth et al. 2012, both in this Theme Section). Macroalgae can also be present at low densities in shallow coastal systems depending on availability of attachment structures or advection of ephemeral populations by wind-driven currents (Thomsen \& McGlathery 2005).

The effect of benthic macrophytes on near-bed hydrodynamics and the resulting sediment/nutrient fluxes may be different at low density than at high density. Extensive research has shown that dense seagrass canopies reduce current velocity (Peterson et al. 2004) and dampen wave energy (Fonseca \& Cahalan 1992), leading to decreased sediment resuspension and increased particle deposition (Heiss et al. 2000, Peterson et al. 2004). Observations of sediment stabilization in seagrass beds and increased turbidity following seagrass decline (e.g. Cottam \& Munro 1954, Christiansen et al. 1981, Stumpf et al. 1999) have supported a conceptual model that sediment suspension increases when seagrass is replaced by macroalgae (e.g. Sand-Jensen \& Borum 1991, Boynton et al. 1996). However, dense macroalgal mats can have similar stabilizing effects. Thick mats decrease sediment suspension (Sfriso \& Marcomini 1997, Romano et al. 2003) and shear flow at the sediment surface (Escartín \& Aubrey 1995). Both dense seagrass meadows (Gambi et al. 1990) and dense macroalgal mats (Escartín \& Aubrey 1995) deflect flow around the bed, creating an area of low shear stress at the sediment surface within the bed. However, research on other types of emergent features in coastal systems, such as polychaete worm tubes, has shown that low-density stands typically displace velocity around individual features, rather than over or around the larger-scale bed/patch, leading to increased erosion around the features (Eckman et al. 1981, Friedrichs et al. 2000, Widdows et al. 2002). When flow is diverted around isolated low-density features, turbulent wake structures can cause areas of high bed shear stress to develop around the features, with the potential to cause scour (e.g. Sadeque et al. 2008), similar to that commonly observed around an isolated bridge pier. Macrophyte density, patch size, and flow velocity interact to determine whether flow, or some portion of the flow, is diverted around the entire bed/patch or individual features. Isolated areas of scour and decreased sediment accumulation have been documented in field, laboratory, and modeling studies of low-density stands of emergent features (Bouma et al. 2007).

Most of the experimental studies to date on the effects of macrophytes on nutrient fluxes across the sediment-water interface have been conducted in artificially-calm hydrodynamic conditions such as stirred laboratory cores or in situ chambers. It is well known that local hydrodynamics influence nutrient fluxes through porewater advection (Huettel \& Webster 2001), desorption from suspended sediments (Morin \& Morse 1999), and thinning of the diffusive boundary layer (Kelly-Gerreyn et al. 2005). Benthic macrophytes can have significant effects on these fluxes physically, by deflecting flow and changing the hydrodynamic conditions at the sediment surface, and biologically, by uptake and indirect effects on bacterial nutrient transformations in the sediment (McGlathery et al. 2007).

Here we report results from a study using controlled microcosm experiments to measure the effects of low-density seagrass and macroalgal populations on sediment suspension and nutrient fluxes. The motivation for this study was the local extinction and subsequent large-scale restoration of the seagrass Zostera marina (eelgrass) in the Virginia coastal bays that are part of the Virginia Coast Reserve Long Term Ecological Research (VCR LTER) site (McGlathery et al. 2012, Orth et al. 2012). Extensive seagrass populations were decimated in this region in the 1930s as a result of 2 natural events: a slime mold wasting disease and a severe hurricane. The loss of eelgrass in the mid-Atlantic region of the USA produced a state change in which the perennial, rooted eelgrass was replaced by ephemeral, attached and drift macroalgae, including the invasive species Gracilaria vermiculophylla. Fishery species, including scallops, declined and turbidity increased (Cottam \& Munro 1954), similar to changes seen in other systems (Stumpf et al. 1999, Yamamuro et al. 2006).

Our experiments were carried out using a smallscale microcosm with controlled hydrodynamic conditions, allowing us to isolate the effects of the primary producers on sediment stability and nutrient fluxes. The use of microcosms with a controlled flow field permits both a mechanistic look at how flow conditions and primary producers interact and direct comparisons between 2 types of primary producers at varying densities. While this approach does not provide ecosystem-level results, microcosm-scale experiments are valuable to direct ecosystem-level studies and parameterize models.

\section{MATERIALS AND METHODS}

To determine the effects of Zostera marina and Gracilaria vermiculophylla on sediment suspension and nutrient flux, sediment cores with varying bio- 
mass were exposed to flow conditions that generate a known bed shear stress in bare sediment cores. Five sampling sites with patchy distributions of eelgrass and macroalgae (attached and detached) were selected randomly within a region of restored eelgrass meadows in South Bay at the VCR LTER site (Fig. 1). At each site, 5 sediment cores ( 4 bare sediment and 1 with eelgrass) were taken. Each site was sampled on 1 day (18 to 22 June 2007), and bare sediment cores were randomly assigned to a control, low macroalgal biomass, medium macroalgal biomass, or high macroalgal biomass treatment (no medium algal biomass treatment was done on Day 3 due to the loss of 1 sediment core). The study was designed as a randomized complete block design, blocked by day and plot, with 5 cores planned per treatment (1 core was lost and 1 was re-classified resulting in 5 cores for all treatments except low algae). Sediment and water column samples were also taken at each site to characterize the sites for any differences in initial conditions.

\section{Shear stress experiments}

Sample collection, storage, and preparation

Sediment samples for the experiments were taken by hand on a falling tide (water depth approximately 0.8 to $1 \mathrm{~m}$ ), within $1 \mathrm{~h}$ of predicted low tide, using

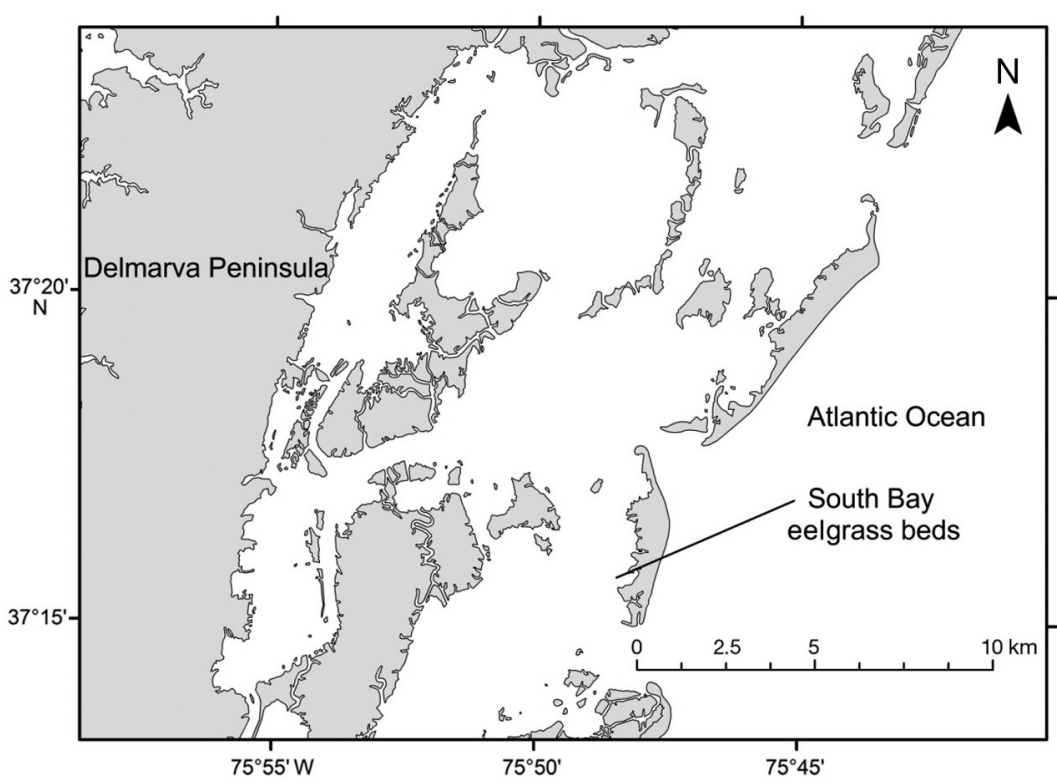

Fig. 1. Study site. South Bay is a shallow coastal lagoon on the east side of the Delmarva Peninsula, USA. Eelgrass transplant efforts and natural recolonization have led to the development of patchy eelgrass beds in the area. Cores with eelgrass or bare sediment were taken in South Bay and exposed to stress under controlled forcing conditions using the Gust erosion microcosm; macroalgae were added to some of the cores polycarbonate core tubes with an internal diameter of $10.8 \mathrm{~cm}$ and a height of $22.5 \mathrm{~cm}$, with a $10 \mathrm{~cm}$ water column preserved above the sediment surface. Core tubes were sealed using rubber plumbing end caps and kept in the dark at $4^{\circ} \mathrm{C}$ during transport back to the lab. Ambient water was collected in 201 carboys to use as replacement water during the experiments and for core storage until analysis. Upon arrival at the lab, within $1 \mathrm{~h}$ of core collection, the cores were submerged in a cooler of ambient water oxygenated by an aquarium bubbler and maintained in low light at ambient temperatures. Macroalgae were collected in South Bay and maintained in a container of ambient water at $4^{\circ} \mathrm{C}$ for transport to the lab, then kept in oxygenated ambient water until use. Immediately prior to the experiment, the overlying water in each sediment core was gently replaced with the same water that would be used for replacement water during the experiment. No sediment suspension or disturbance was noted during this step.

Bare sediment cores were assigned randomly to 1 of 4 treatments (control, low macroalgae, medium macroalgae, and high macroalgae), and analysis order of the treatments was assigned randomly. Macroalgae treatments were defined as 2 (low), 4 (medium), or 6 (high) g wet weight (WW) of macroalgae, standardized by blotting excess water with a paper towel. Macroalgae were added to a bare sediment core immediately before the start of the experiment. At the end of the experiment, the macroalgae were collected and dried at $60^{\circ} \mathrm{C}$ to a constant weight to determine dry weight (DW) biomass. The macroalgae treatments, based on the average field biomass of $54 \mathrm{~g}$ DW $\mathrm{m}^{-2}$ found in an adjacent bay (Thomsen et al. 2006), resulted in a range of dry biomass with averages \pm SE of $18 \pm$ $0.83 \mathrm{~g} \mathrm{DW} \mathrm{m}^{-2}$ (low), $37 \pm 2.1 \mathrm{~g} \mathrm{DW} \mathrm{m}^{-2}$ (medium), and $66 \pm 4.4 \mathrm{~g} \mathrm{DW} \mathrm{m} \mathrm{m}^{-2}$ (high).

Height limitations of the microcosm required eelgrass to be trimmed to a maximum height of $8 \mathrm{~cm}$ prior to running the experiments. Trimming to this height allowed the blades to remain submerged without interfering with the functioning of the microcosm. While the trimming created shoots that were shorter than found in the field during June (the time of this experiment), the shorter length is representative of early spring and late fall shoots found 
in the nearby Chesapeake Bay (Orth \& Moore 1986). The eelgrass cut at the beginning of the experiment was dried at $60^{\circ} \mathrm{C}$ and weighed. At the end of the experiment, all remaining eelgrass aboveground biomass was cut and also dried and weighed so that the biomass of the eelgrass cut before the experiment, the aboveground biomass in the cores during the experiment, and the total aboveground biomass could be calculated for each core. Total aboveground biomass of the eelgrass (before trimming) in the cores ranged from 64 to $470 \mathrm{~g} \mathrm{DW} \mathrm{m}^{-2}$. This is comparable to 76 to 558 shoots $\mathrm{m}^{-2}$, based on field measurements of densities and biomass per shoot from the study site (McGlathery et al. 2012). The aboveground biomass of the eelgrass in the cores during the experiments (i.e. the $8 \mathrm{~cm}$ tall blades that remained after trimming) ranged from 41 to $184 \mathrm{~g} \mathrm{DW} \mathrm{m}^{-2}$.

\section{Shear stress manipulation}

The Gust microcosm used in these experiments consisted of an erosion head with a rotating plate and a push-through water system fitted over a polycarbonate core tube (Fig. 2; Thomsen \& Gust 2000). With a level, bare sediment bed, the combination of the rotation of the plate and the suction of the water system in the center of the core generates a nearuniform bed shear stress and diffusive boundary

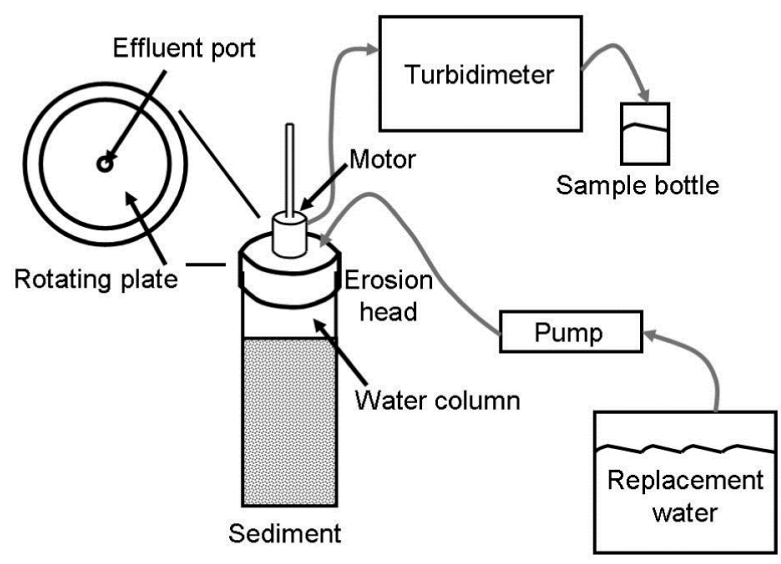

Fig. 2. Gust erosion microcosm. The erosion head contains inflow and outflow ports and a rotating plate that generates a flow producing a relatively uniform shear stress on the sediment surface of a core sample. The rotation and pumping rates are controlled by a datalogger. The turbidity from the effluent is continuously recorded on the turbidimeter, and the outflow is collected in a sample bottle for filtering. The measured sample volumes and sediment and nutrient concentrations were used to calculate fluxes for bare sediment, 3 densities of macroalgae, and seagrass cores layer thickness, though not a uniform pressure distribution (Tengberg et al. 2004). Because sediment conditions were similar between treatments and the hydrodynamic forcing was controlled, changes in sediment suspension should be a direct result of alterations to the near-bed hydrodynamics. Across treatments, any increase in the mass of sediment eroded from the bed should reflect localized increases in bed shear stress caused by the treatment. The use of Gust microcosms for studying benthic fluxes is further examined in the 'Discussion'.

Immediately prior to the experiment, a water sample was pumped from the replacement water to provide background concentration values. The cores were then exposed to low forcing conditions (forcing that produces a low shear stress of $0.01 \mathrm{~N} \mathrm{~m}^{-2}$ in bare sediment cores) for $20 \mathrm{~min}$ as a flushing step, followed by high forcing conditions (forcing that produces a shear stress of $0.32 \mathrm{~N} \mathrm{~m}^{-2}$ in bare sediment cores) for $40 \mathrm{~min}$. This shear stress is in the range of storm-generated bed shear stresses in the VCR (Lawson et al. 2007, Mariotti et al. 2010) and roughly corresponds to an average velocity of $0.25 \mathrm{~m} \mathrm{~s}^{-1}$ in the microcosm (without obstructions), similar to the flow rates used in other studies of sediment suspension/stabilization in Zostera marina beds (e.g. Fonseca \& Fisher 1986). Effluent water was collected in 11 Nalgene bottles exchanged every $5 \mathrm{~min}$ for the higher shear stresses. All effluent water from the erosion tests was collected, subsampled, and filtered for total suspended solids (TSS), $\mathrm{NH}_{4}{ }^{+}, \mathrm{PO}_{4}{ }^{3-}$, and $\mathrm{NO}_{3}{ }^{-}$. No fragmentation of macroalgae or eelgrass was noted during the experiments.

\section{Site characterization}

Bottom sediment samples were taken at each plot to characterize porewater nutrients, sediment grain size, exchangeable ammonium $\left(\mathrm{NH}_{4}{ }^{+}\right)$, and benthic chlorophyll. Five replicate samples for grain size and $\mathrm{NH}_{4}{ }^{+}$were taken to a depth of $2 \mathrm{~cm}$ with a modified $60 \mathrm{ml}$ syringe, and 5 replicate samples for benthic chlorophyll were taken to $1 \mathrm{~cm}$ depth with a modified $5 \mathrm{ml}$ syringe. Three replicate sediment cores were collected in polycarbonate tubes $(8 \mathrm{~cm}$ internal diameter, $23 \mathrm{~cm}$ height) for laboratory sampling of porewater. All samples were kept at $4^{\circ} \mathrm{C}$ during transport to the lab. Samples for benthic chlorophyll and extractable $\mathrm{NH}_{4}{ }^{+}$were immediately frozen; grain size samples were maintained at $4^{\circ} \mathrm{C}$ until analysis. Porewater samples were extracted from the sediment cores at $2 \mathrm{~cm}$ depth intervals to $10 \mathrm{~cm}$ depth using a 
stainless steel probe (Berg \& McGlathery 2001) and were immediately filtered $(0.45 \mu \mathrm{m})$ and frozen. Exchangeable $\mathrm{NH}_{4}{ }^{+}$was extracted for $1 \mathrm{~h}$ with an equal volume of $1 \mathrm{~N} \mathrm{KCl}$ solution. Porewater samples (for $\mathrm{NH}_{4}{ }^{+}$, phosphate $\mathrm{PO}_{4}{ }^{3-}$, and nitrate+nitrite $\mathrm{NO}_{3}{ }^{-}$), and exchangeable $\mathrm{NH}_{4}{ }^{+}$samples were analyzed on a Lachat QuickChem 8500 using standard methods (Hach). Benthic chlorophyll was determined spectrophotometrically following extraction with a $45 \%$ acetone, $45 \%$ methanol, $10 \%$ deionized water solution using the equations of Lorenzen (1967). Sediment grain size was analyzed as 1 bulk sample per plot, from 5 pooled samples (0 to $2 \mathrm{~cm}$ depth), using a combination of wet sieving for sands and analysis on a Sedigraph 5100 particle size analyzer for silt and clay.

\section{Laboratory analyses}

All sediment and water samples were analyzed using standard methods. TSS (sample volumes 150 to $550 \mathrm{ml}$ ) was analyzed by weight difference after filtration onto pre-combusted, pre-weighed Whatmann $\mathrm{GF} / \mathrm{F}$ filters (nominal particle retention $0.7 \mu \mathrm{m}$ ). Subsamples for nutrients $(20 \mathrm{ml})$ were filtered $(0.45 \mu \mathrm{m})$ and frozen until analysis. $\mathrm{NH}_{4}{ }^{+}, \mathrm{PO}_{4}{ }^{3-}$, and $\mathrm{NO}_{3}{ }^{-}$ were analyzed using standard methods on a Lachat QuikChem 8500 (as described above). $\mathrm{NO}_{3}^{-}$and nitrite $\left(\mathrm{NO}_{2}{ }^{-}\right)$were not separated because $\mathrm{NO}_{2}{ }^{-}$ values were frequently below the detection level. The combined value is presented as $\mathrm{NO}_{3}{ }^{-}$throughout this study.

To correct for the mass of measured components carried in the replacement water, all fluxes were corrected for background concentration. For the nutrient fluxes, the average concentration of all background samples for the day was used as the background concentration. For the mass of sediment eroded, the lowest measured concentration of TSS during the analysis of the core was used. Data from the flushing step were discarded, and only data from the higher shear stress step were analyzed. One macroalgal treatment was reclassified (from low to medium) at the end of the experiment based on the measured DW of the macroalgae $\left(33 \mathrm{~g} \mathrm{DW} \mathrm{m}^{-2}\right)$.

\section{RESULTS}

\section{Site characterization}

We found no significant differences in the initial conditions at the 5 plots in South Bay (Table 1). Sediment extractable $\mathrm{NH}_{4}{ }^{+}$ranged from 0.065 to $0.087 \mu \mathrm{mol} \mathrm{g} \mathrm{DW} \mathrm{DW}^{-1}$ with an average $\pm \mathrm{SE}$ of $0.08 \pm$ $0.00 \mu \mathrm{mol} \mathrm{g} \mathrm{DW}{ }^{-1}$. Porewater concentrations of $\mathrm{NH}_{4}{ }^{+}$ ranged from 0 to $152 \mu \mathrm{M}, \mathrm{PO}_{4}{ }^{3-}$ from 0 to $16 \mu \mathrm{M}$, and $\mathrm{NO}_{3}{ }^{-}$from 1.2 to $6 \mu \mathrm{M}$. The sediment in all plots was very fine sand, with between 5 and $11 \%$ mud (average grain size $=71 \mu \mathrm{m})$. Water column nutrient concentrations, as measured from the replacement water, were $0.5 \pm 0.1 \mu \mathrm{M} \mathrm{NH}_{4}{ }^{+}, 0.4 \pm 0.1 \mu \mathrm{M} \mathrm{PO}_{4}{ }^{3-}$, and $0.3 \pm 0.1 \mu \mathrm{M} \mathrm{NO}_{3}{ }^{-}$, similar to values measured in neighboring Hog Island Bay (McGlathery et al. 2001).

\section{Sediment suspension}

During the $40 \mathrm{~min}$ high-forcing experiments, an average of $0.26 \pm 0.03 \mathrm{~g}$ of sediment was eroded for all treatments, which is equivalent to an average erosion depth of $2.8 \times 10^{-3} \mathrm{~m}$, assuming a bulk density (DW of sediment per unit volume of bed) of $1.0 \mathrm{~g} \mathrm{~cm}^{-3}$, or $28.7 \mathrm{~g} \mathrm{~m}^{-2}$ (see Figs. $3 \& 4$ ). There was no significant effect of eelgrass presence on sediment suspension compared to bare sediment for the flow conditions and biomass used in these experiments (paired $t$-test, $\mathrm{p}=0.4$, Fig. 3). However, closer analysis of the variation in eelgrass biomass within the replicate cores indicates that at low biomass (corresponding to shoot densities of approximately 76 to

Table 1. Summary of site characteristics for each plot in South Bay. All plots showed similar sediment and nutrient conditions. Values are averages (SE) of samples as described in 'Materials and methods'

\begin{tabular}{|cccccccccc}
\hline $\begin{array}{c}\text { Average } \\
\text { grain size } \\
(\mu \mathrm{m})\end{array}$ & $\begin{array}{c}\text { Benthic } \\
\text { chlorophyll } \\
\left(\mathrm{mg} \mathrm{m}^{-2}\right)\end{array}$ & $\begin{array}{c}\mathrm{NH}_{4}{ }^{+} \\
(\mu \mathrm{M})\end{array}$ & $\begin{array}{c}\mathrm{PO}_{4}{ }^{3-} \\
(\mu \mathrm{M})\end{array}$ & $\begin{array}{c}\mathrm{NO}_{3}{ }^{-} \\
(\mu \mathrm{M})\end{array}$ & $\begin{array}{c}\text { Extractable } \\
\mathrm{NH}_{4}{ }^{+}\end{array}$ & $\mathrm{NH}_{4}{ }^{+}(\mu \mathrm{M})$ & $\mathrm{PO}_{4}{ }^{3-}\left(\mu \mathrm{M}^{-}\right)$ & $\mathrm{NO}_{3}{ }^{-}(\mu \mathrm{M})$ \\
\hline Day 1 & 76 & $4.7(0.8)$ & $0.4(0.2)$ & $0.3(0.1)$ & $0.5(0.1)$ & $0.06(0.00)$ & $62(5)$ & $4.3(0.5)$ & $2.2(0.2)$ \\
Day 2 & 70 & $5.2(0.2)$ & $0.2(0.1)$ & $0.2(0.0)$ & - & $0.09(0.00)$ & $43(5)$ & $3.5(0.6)$ & $1.7(0.3)$ \\
Day 3 & 76 & $5.6(0.9)$ & $0.6(0.2)$ & $0.4(0.2)$ & $0.2(0.1)$ & $0.08(0.00)$ & $82(7)$ & $5.7(0.4)$ & $2.0(0.1)$ \\
Day 4 & 67 & $4.5(0.6)$ & $0.6(0.1)$ & $0.4(0.0)$ & $0.3(0.1)$ & $0.07(0.00)$ & $34(9)$ & $4.7(0.2)$ & $2.6(0.3)$ \\
Day 5 & 66 & $6.1(0.8)$ & $0.7(0.1)$ & $0.5(0.2)$ & $0.3(0.2)$ & $0.08(0.02)$ & $42(3)$ & $3.4(0.5)$ & $2.6(0.3)$ \\
\hline
\end{tabular}



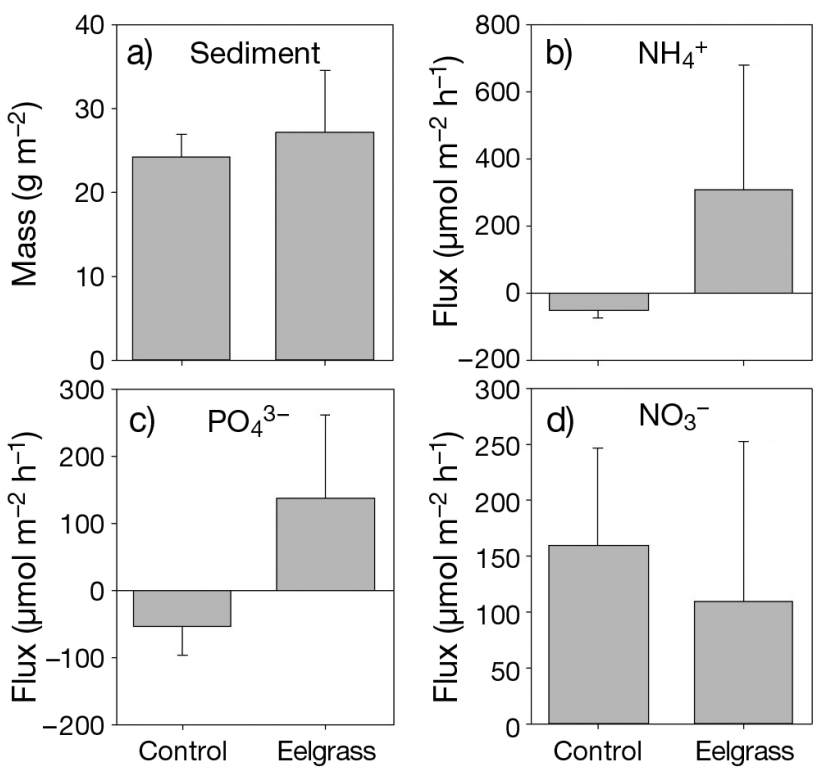

Fig. 3. Summary of sediment eroded and nutrient flux for eelgrass (error bars $=\mathrm{SE}_{;} \mathrm{n}=5$ ). (a) Mass of sediment eroded, (b) $\mathrm{NH}_{4}{ }^{+}$flux, (c) $\mathrm{PO}_{4}{ }^{3-}$ flux, and (d) $\mathrm{NO}_{3}{ }^{-}$flux. Nutrient fluxes generally mirrored the mass of sediment eroded, although SEs were large. The variability of densities and lack of replicates at different eelgrass densities make comparisons between the control and eelgrass cores difficult and lead to no significant differences between sediment suspension in eelgrass and control cores (paired $t$-test, $\mathrm{p}=0.4$ )

239 shoots $\mathrm{m}^{-2}$ ), sediment suspension appeared to increase with increasing biomass, whereas at higher biomass, sediment suspension dropped to almost 0 . Moore (2004) found a lack of sediment trapping in seagrass beds of similar low biomass, but a mechanistic look at internal resuspension has not previously been conducted. A more complete understanding of the structure of this relationship and the biomass or density corresponding to peak suspension would require considerably more data than are available in these experiments and is beyond the scope of this study. However, the existence of conditions in which seagrass may de-stabilize, rather than stabilize, sediment beds is considered in the 'Discussion'.

Macroalgal biomass had a significant effect on sediment suspension, with an initial increase above control values for the low biomass treatment, followed by a decrease for the medium and high biomass treatments (ANOVA, $\mathrm{p}=0.04, \mathrm{n}=14$, Fig. 4). If we take into account the variability in macroalgal biomass for each replicate and consider the macroalgal biomass, excluding the control, as a continuous variable, the mass of sediment eroded was strongly negatively dependent on biomass $\left(\mathrm{R}^{2}=0.55, \mathrm{p}=\right.$ $0.002, \mathrm{n}=14$, Fig. 5). The control treatment was excluded from this regression analysis because of the initial increase in sediment erosion from the control to low biomass treatments.

\section{Nutrient flux}

For the macroalgae treatments, the $\mathrm{NH}_{4}{ }^{+}$and $\mathrm{PO}_{4}{ }^{3-}$ fluxes showed a similar pattern to the sediment suspension, with an increase in flux between the control and low biomass treatment, followed by a decrease for the medium and high biomass treatments (Fig. 4). Although high variability in nutrient fluxes within each treatment resulted in no significant differences between treatments for macroalgae (ANOVA, $\mathrm{NH}_{4}{ }^{+}$ $\mathrm{p}=0.9, \mathrm{PO}_{4}{ }^{3-} \mathrm{p}=0.4, \mathrm{NO}_{3}{ }^{-} \mathrm{p}=0.2$ ) or eelgrass ( $t$-test, $\mathrm{NH}_{4}{ }^{+} \mathrm{p}=0.2, \mathrm{PO}_{4}{ }^{3-} \mathrm{p}=0.08, \mathrm{NO}_{3}{ }^{-} \mathrm{p}=0.4$ ), some trends in the data are apparent. The sediment flux was related to the $\mathrm{NH}_{4}{ }^{+}$flux $\left(\mathrm{R}^{2}=0.98, \mathrm{p}=0.007\right.$, Fig. 6) for the macroalgal treatments and the control. The close relationship between macroalgal biomass and mass of sediment eroded (Fig. 5) makes it difficult to distinguish effects of nutrient uptake by macroalgae from effects of hydrodynamic forcing.

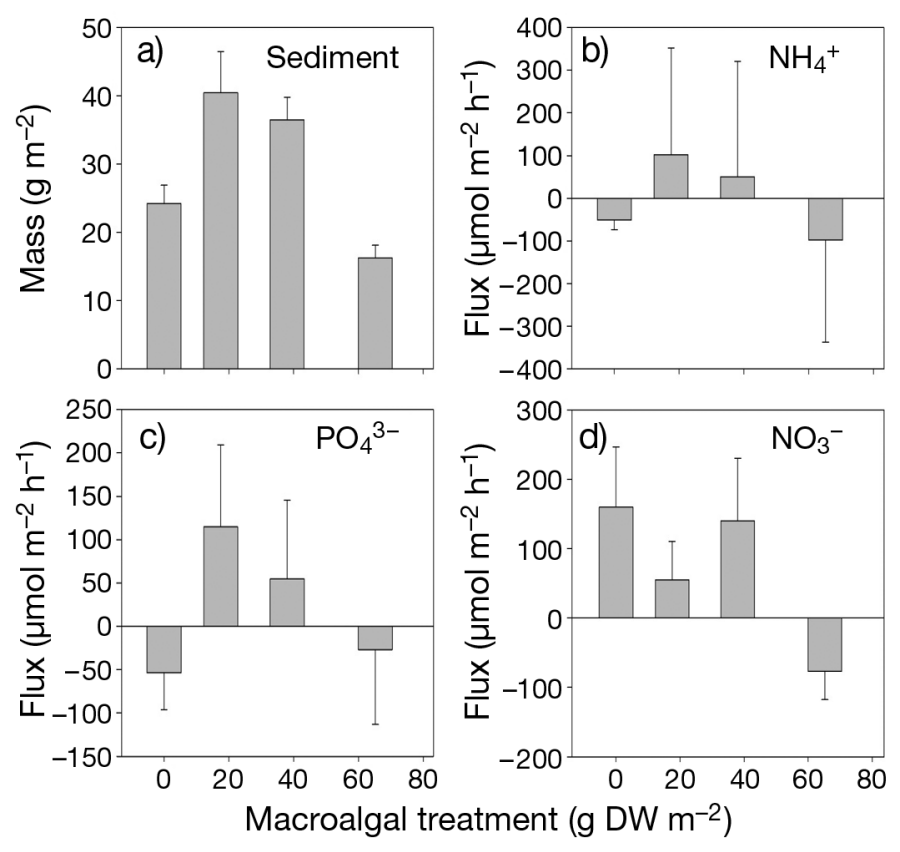

Fig. 4. Summary of sediment eroded and nutrient fluxes for the macroalgae treatments (error bars $=\mathrm{SE}_{;} \mathrm{n}=5$ for control, medium, and high biomass treatments, $\mathrm{n}=4$ for low biomass). (a) Mass of sediment eroded, (b) $\mathrm{NH}_{4}{ }^{+}$flux, (c) $\mathrm{PO}_{4}{ }^{3-}$ flux, and (d) $\mathrm{NO}_{3}{ }^{-}$flux. The mass of sediment eroded varied with macroalgal biomass (ANOVA, $\mathrm{p}=0.04, \mathrm{n}=14$ ), with an increase at low biomass (18 $\mathrm{g}$ dry weight, $\mathrm{DW}, \mathrm{m}^{-2}$ ) followed by a decrease at higher biomasses ( 37 and $54 \mathrm{~g} \mathrm{DW} \mathrm{m}^{-2}$ ). Nutrient fluxes did not vary significantly but generally mirrored the mass of sediment eroded 


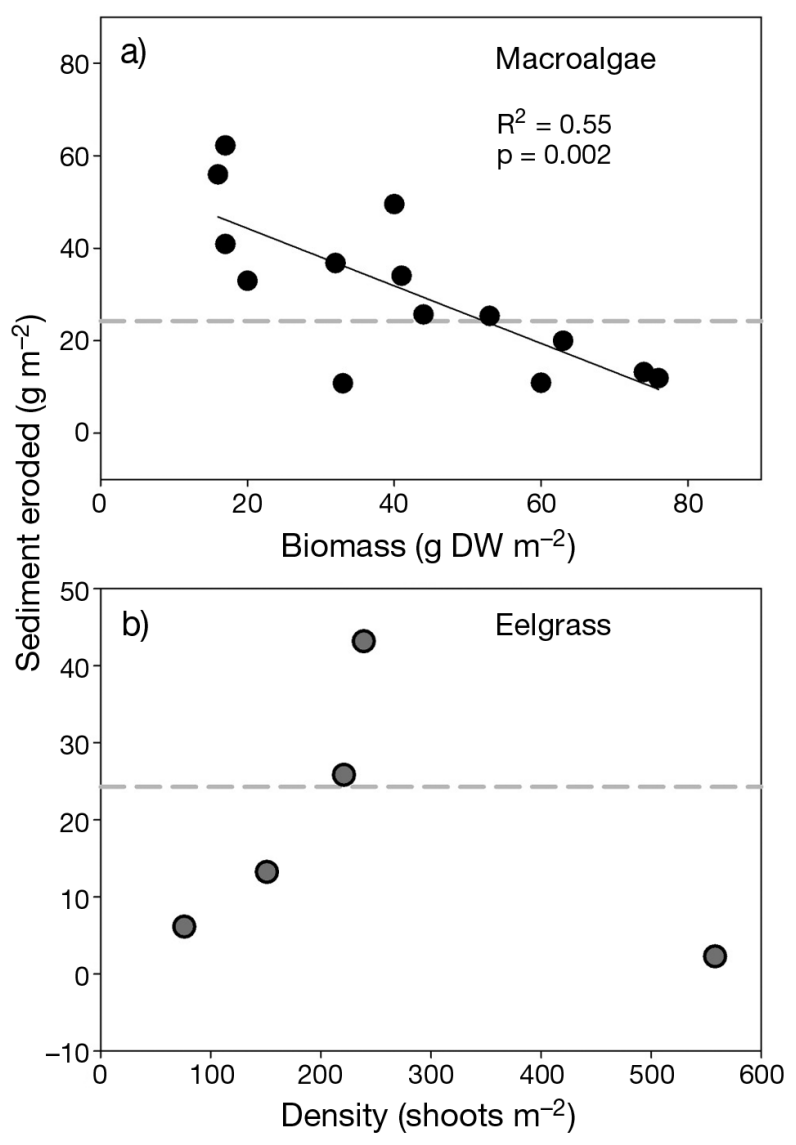

Fig. 5. Relationship between suspended sediment and primary producer biomass. (a) Macroalgae showed decreased suspension with increasing biomass $\left(R^{2}=0.55, p=0.002\right)$, but sediment suspension at low biomass was higher than control levels (dashed gray line). (b) Eelgrass showed increasing suspension with increasing biomass, a novel finding compared to characterization of seagrass as a sediment stabilizer. The range of eelgrass biomass that showed increasing suspension is roughly equivalent to 76 to 239 shoots $\mathrm{m}^{-2}$. Sediment suspension is presented as the total mass eroded scaled to $1 \mathrm{~m}^{2}$ area for the duration of the high flow conditions (40 min). Sediment suspension is not scaled to the hour because the sediment flux would likely decrease over time,

consistent with Type I erosion (Sanford \& Maa 2001)

However, if nutrient fluxes were dependent on biomass, the control point would not fit the regression of mass of sediment eroded and nutrient flux, because the control point is not part of the linear relationship between mass of sediment eroded and biomass (Fig. 4).

\section{DISCUSSION}

Our data provide evidence that low-biomass macroalgal populations can increase both sediment suspension and nutrient efflux under high-flow con-

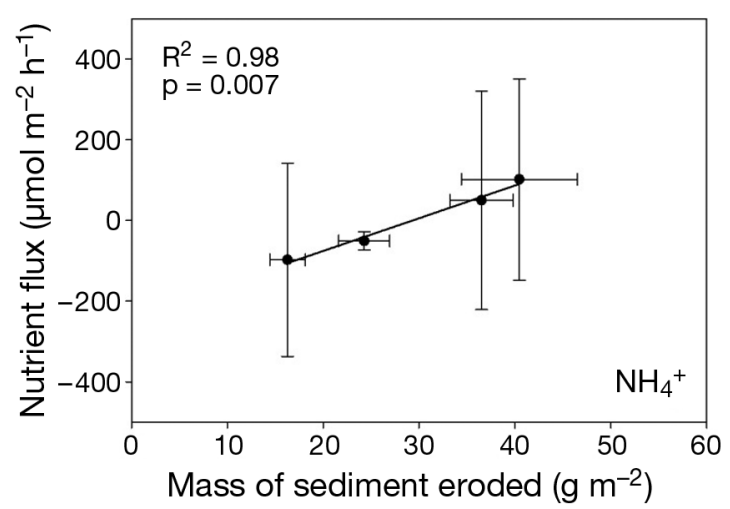

Fig. 6. Relationships between nutrient flux and mass of sediment eroded (error bars $=\mathrm{SE}$ ). Flux of $\mathrm{NH}_{4}{ }^{+}\left(\mathrm{R}^{2}=0.98, \mathrm{p}=\right.$ 0.007 ) is positively correlated with mass of sediment eroded for the macroalgal treatments and the control (second point from the left). This relationship indicates that when shear stresses are high and macroalgal biomass is low macroalgae may increase the nutrient efflux from the sediment. In coastal bays in which macroalgae typically reduce the flux of nutrients from the sediment to the water column, this may be an important process for supplying nutrients to pelagic producers

ditions. The data also suggest that at low densities, seagrass may not be effective at stabilizing sediment and may in fact enhance sediment suspension. Most previous research on high-biomass populations has shown that seagrass and macroalgal mats reduce sediment suspension (Sfriso \& Marcomini 1997, Heiss et al. 2000, Romano et al. 2003, Peterson et al. 2004) and nutrient efflux (Thybo-Christesen et al. 1993, Sundback et al. 2000, McGlathery et al. 2004, 2007), although recent experiments on macroalgae by CanalVergés et al. (2010) are an exception. Because our results differ from those of most previous studies, these experiments give insight into conditions that may favor sediment destabilization by benthic primary producers.

\section{Applicability of microcosm studies to field conditions}

While microcosms can never exactly mimic field conditions, the Gust microcosm has been widely used to represent near-bed flows for the purpose of measuring benthic fluxes (Ziervogel \& Bohling 2003, Porter et al. 2004a, Stevens et al. 2007, Dickhudt et al. 2009, Wiberg et al. in press). The Gust microcosm creates a relatively uniform bed shear stress through the action of a spinning plate just below the water surface and a push-through water system. With this forcing, flow paths in the Gust microcosm occur in a logarithmic spiral with an upward vortex in the mid- 
dle of the core (Thomsen \& Gust 2000). Because the flow path includes a significant vertical component, it more closely resembles shallow wave action or a combined wave-current flow than a simple uniform current, which is appropriate for shallow lagoons where wave forcing is dominant (Lawson et al. 2007, Mariotti et al. 2010). Gust microcosms have been used to measure benthic fluxes on sediment cores from a wide range of environments, including the Baltic Sea (Ziervogel \& Bohling 2003), Adriatic shelf (Stevens et al. 2007), Chesapeake Bay tributaries (Porter et al. 2004a, Dickhudt et al. 2009), the northern Atlantic off the coast of the UK (Black et al. 2003), and tidal flats in southwest Washington State, USA (Wiberg et al. in revision). Sediment erodibility measured using Gust microcosms has been shown to compare well with measurements made using other techniques (e.g. in situ inverted flume; Dickhudt et al. 2009) and to yield calculated suspended sediment concentrations in good agreement with field measurements (Traykovski et al. 2007).

An extensive comparison of the Gust microcosm and other benthic chambers showed that the Gust microcosm produced the most uniform bed shear stress and diffusive boundary layer thickness of the chambers studied (Tengberg et al. 2004). This uniformity is important when introducing obstructions to the chamber, making the Gust microcosm an appropriate choice for this experiment. To confirm that the forcing conditions chosen for the experiments reasonably reflect the forcing conditions in benthic environments, the ratio of mean velocity $\left(0.25 \mathrm{~m} \mathrm{~s}^{-1}\right)$ to the shear velocity $\left(0.018 \mathrm{~m} \mathrm{~s}^{-1}\right.$, assuming a saltwater density of $1030 \mathrm{~kg} \mathrm{~m}^{-3}$ ) in the chamber was compared with the ratios found in natural benthic environments (Porter et al. 2004b). The calculated value for the flow conditions without obstructions (14.1) is within the range seen in natural environments (13.9 to 22.8, Porter et al. 2004b). The presence of macrophytes is expected to decrease average bed shear stress because of drag on the macrophytes.

\section{Stabilizing versus destabilizing effects of seagrass}

Sediment stabilization from seagrass beds typically occurs due to the high flow resistance offered by a dense seagrass bed (Gambi et al. 1990, Bouma et al. 2007). However, at low densities and high-flow rates, water predominantly moves through, rather than over or around a seagrass bed. In sparse seagrass beds, suspended sediment concentrations may be equal to those in unvegetated areas because the tur- bulent stresses are similar (Luhar et al. 2008). The interaction of flow with individual shoots causes wakes to form behind the shoots. At Reynolds numbers, $\operatorname{Re}=U d / v>\approx 200$, where $U$ is velocity, $d$ is shoot diameter, and $v$ is kinematic viscosity, the wakes are turbulent (Nepf 1999). At relatively low shoot densities, increases in wake-generated turbulence production can be large enough relative to frictional decreases in velocity to cause an increase in turbulent kinetic energy (Nepf 1999) and local bed shear stresses (Sadeque et al. 2008) when vegetation is present compared to unvegetated conditions. If the wake-generated shear stresses at the bed exceed the critical shear stress of the bed sediment, scour and increased sediment suspension can result, as seen with other isolated emergent features (e.g. Eckman et al. 1981, Friedrichs et al. 2000, Widdows et al. 2002). Assuming a representative blade width of $3 \mathrm{~mm}$ (Hansen \& Reidenbach 2012, this Theme Section), $\operatorname{Re} \approx 600$ for our experiments.

In addition to density and flow velocity, flow characteristics (i.e. wave or current dominated) may affect the ability of the seagrass to stabilize sediment. When seagrass is exposed to wave forcing, a mean current is generated within the canopy rather than a skimming flow developing over the top of the canopy (Luhar et al. 2010). Also, while seagrass blades in unidirectional flow bend and physically shield the sediment bed, seagrass blades in oscillatory flows move with the flow and can enhance the exchange between the sediment bed and the water column (Koch \& Gust 1999). Taller seagrass in unidirectional flow may shield the bed (as noted by Fonseca \& Fisher 1986); however, short seagrass shoots that are more representative of early spring and late fall conditions in the field do not provide bed shielding in wave-like flow conditions. Previous research has shown that these low-density and low-biomass beds are ineffective at trapping suspended sediment under riverine conditions (Moore 2004), but their influence on internal resuspension and wave-dominated flows has not been studied.

\section{Stabilizing versus destabilizing effects of macroalgae}

Density and flow conditions may have similar effects on the ability of macroalgae to stabilize sediments. While dense macrolgal mats deflect flow around the mat (Gambi et al. 1990, Escartín \& Aubrey 1995) similar to dense seagrass beds, isolated individual or individuals in patchy distributions are directly exposed to the undisturbed flow conditions. 
Macroalgae such as Gracilaria vermiculophylla, which are frequently found detached, are often transported as bedload. Bedload transport of macroalgae is an important component of macroalgal transport (Flindt et al. 1997, 2004), and has been shown to significantly increase sediment suspension at densities of 17 to $33 \mathrm{~g} \mathrm{DW} \mathrm{m}^{-2}$ (Canal-Vergés et al. 2010). Combining that study with the results of our experiment and the results seen in high-density mats (Escartín \& Aubrey 1995, Sfriso \& Marcomini 1997, Romano et al. 2003, Sfriso et al. 2005) shows that high-biomass populations of macroalgae stabilize sediment while lowbiomass populations destabilize sediment. Given the high seasonal variability in macroalgal biomass (e.g. Thomsen et al. 2006), the stabilizing/destabilizing effect of macroalgae is also likely seasonal. A vertical component of flow, found in the microcosm and in wave-dominated flows, may make the macroalgae more likely to be transported because fronds are lifted away from the bed and into the faster-moving flow in the water column, whereas in unidirectional flows, the macroalgae likely lie closer to the sediment surface. The movement of these fronds in currentversus wave-dominated flows may be analogous to the differences seen in seagrass movement in unidirectional and oscillatory flow conditions (Koch \& Gust 1999).

Bedload transport of macroalgae can destabilize sediments by dislodging particles in a process similar to the widely documented increase in sediment suspension due to saltating or abrading particles (e.g. Houser \& Nickling 2001, Thompson \& Amos 2002, 2004). In fine-grained beds, the critical shear stress required to initiate erosion is often greater than the stress required to maintain the sediment in suspension. Under these conditions, an object (e.g. macroalgae) that impacts or scrapes the bed while moving across it can dislodge particles and significantly increase sediment suspension/erosion. We observed higher sediment erosion in experiments in which the macroalgae were in motion compared to cases in which the macroalgae were stationary.

\section{Factors affecting nutrient fluxes}

The results of this study show that the effects of macrophytes on benthic nutrient fluxes are not limited to biotic effects. Modification of near-bed flow by benthic macrophytes can influence sediment-water column nutrient fluxes. Field and modeling studies have shown that increased hydrodynamic activity and sediment suspension influenced nutrient flux in areas such as Lake Okeechobee, Florida, USA (Chen \& Sheng 2003, 2005), the Satilla River Estuary, Georgia, USA (Zheng et al. 2004), and the Mediterranean shelf (Gremare et al. 2003). Modification of near-bed flow by benthic primary producers can produce similar effects. Benthic primary producers are well known to indirectly affect nutrient cycling, including effects on nitrogen fixation, nitrification, and nitrification/denitrification (e.g. Viaroli et al. 1996, Hansen et al. 2000, McGlathery et al. 2004). Nutrient uptake by benthic primary producers can also significantly reduce the flux of remineralized nutrients to the water column (Thybo-Christesen et al. 1993, Sundbäck et al. 2000, McGlathery et al. 2004, 2007). The total impact of benthic primary producers on the flux of nutrients between the sediment and water column is thus the result of both physical modification and biotic influences, yet these have rarely been studied in tandem.

Our data suggest that the effect of primary producers on nutrient flux during a forcing event depends on the balance between uptake and physical modification of the flow near the sediment surface. In low-flow cores or microcosm incubations, it has been shown that benthic algae can prevent the efflux of nutrients from the sediment to the water column (e.g. Sundbäck et al. 2000, Tyler et al. 2001), with the balance between benthic autotrophy and heterotrophy having a significant influence on nutrient efflux (Eyre \& Ferguson 2002). This uptake effectively decouples nutrient cycling in the sediment and the water column (Kristensen et al. 2000, Anderson et al. 2003). Our results show that when macroalgal biomass is low and flow conditions are relatively high, physical dynamics result in an enhancement of nutrient flux to the water column in addition to increased sediment suspension. This can be seen in the relationship between sediment suspension and $\mathrm{NH}_{4}{ }^{+}$ fluxes (Fig. 6). Under high-flow conditions, processes such as porewater advection and desorption of nutrients from suspended particles increase nutrient fluxes above the levels supported by diffusion alone (Ward et al. 1984, Huettel et al. 1998, Morin \& Morse 1999). The movement of algae caused by the increased shear stress likely enhances this effect. In a related study, we investigated the mechanisms accounting for the increased nutrient efflux from sediments in our microcosm experiments and showed that hydrodynamically-forced fluxes (advection, suspension/ desorption) were similar in magnitude to diffusive fluxes, indicating that low-flow incubations may underestimate nutrient fluxes by $50 \%$ if higher flows are present (Lawson 2008). 
In summary, our data show that seagrass and macroalgae can have both stabilizing and destabilizing effects on the sediment when exposed to forcing conditions that reflect the high flows representative of storm conditions in shallow bays. Low biomass, or densities, of macroalgae can destabilize sediments, leading to increased sediment suspension and nutrient efflux; the same may be true of low-density seagrass beds. The mechanisms responsible for the destabilization are different for the 2 macrophyte functional groups: increases in near-bed turbulence as flow moves through seagrass shoots versus dislodgement of sediment particles by bedload transport of macroalgae. The threshold between stabilizing and destabilizing effects is biomass-dependent, and suggests a 'window of vulnerability' to negative feedbacks when biomass or densities are low and flows are high. This is relevant to restored seagrass populations where seeding results in initially lowdensity populations that eventually increase in biomass and density as the meadow develops over time. It is also relevant to shallow coastal systems that have been impacted by nutrient over-enrichment where multiple stresses create patchiness and thinning of seagrass populations, and macroalgal biomass may accumulate on seasonal time scales.

Acknowledgements. We thank Rachel Hippert, Rachel Baker, Jason Turner, and the staff of the Virginia Coast Reserve LTER for field assistance. Partial support was provided by the Virginia Coast Reserve LTER project, which is funded by National Science Foundation grant DEB-0621014.

\section{LITERATURE CITED}

Anderson IC, McGlathery KJ, Tyler AC (2003) Microbial mediation of 'reactive' nitrogen transformations in a temperate lagoon. Mar Ecol Prog Ser 246:73-84

Berg P, McGlathery KJ (2001) A high-resolution pore water sampler for sandy sediments. Limnol Oceanogr 46:203-210

Black KS, Peppe OC, Gust G (2003) Erodibility of pelagic carbonate ooze in the northeast Atlantic. J Exp Mar Biol Ecol 285-286:143-163

> Bouma TJ, van Duren LA, Temmerman S, Claverie T, Blanco-Garcia A, Ysebaert T, Herman PMJ (2007) Spatial flow and sedimentation patterns within patches of epibenthic structures: combining field, flume and modeling experiments. Cont Shelf Res 27:1020-1045

> Boynton WR, Hagy JD, Murray L, Stokes C, Kemp WM (1996) A comparative analysis of eutrophication patterns in a temperate coastal lagoon. Estuar Coasts 19:408-421

> Canal-Vergés P, Vedel M, Valemarsen T, Kristensen E, Flindt MR (2010) Resuspension created by bedload transport of macroalgae: implications for ecosystem functioning. Hydrobiologia 649:69-76

> Chen XJ, Sheng YP (2003) Modeling phosphorus dynamics in a shallow lake during an episodic event. Lake Reser- voir Manag 19:323-340

Chen XJ, Sheng YP (2005) Three-dimensional modeling of sediment and phosphorus dynamics in Lake Okeechobee, Florida: spring 1989 simulation. J Environ Eng 131:359-374

Christiansen C, Christoffersen H, Dalsgaard J, Nornberg P (1981) Coastal and near-shore changes correlated with die-back in eel-grass (Zostera marina, L.). Sediment Geol 28:163-173

> Cottam C, Munro DA (1954) Eelgrass status and environmental relations. J Wildl Manag 18:449-460

> Dickhudt PJ, Friedrichs CT, Schaffner LC, Sanford LP (2009) Spatial and temporal variation in cohesive sediment erodibility in the York River estuary, eastern USA: a biologically influenced equilibrium modified by seasonal deposition. Mar Geol 267:128-140

> Duarte CM (2002) The future of seagrass meadows. Environ Conserv 29:192-206

Eckman JE, Nowell ARM, Jumars PA (1981) Sediment destabilization by animal tubes. J Mar Res 39:361-374

Escartín J, Aubrey DG (1995) Flow structure and dispersion within algal mats. Estuar Coast Shelf Sci 40:451-472

> Eyre BD, Ferguson AJP (2002) Comparison of carbon production and decomposition, benthic nutrient fluxes and denitrification in seagrass, phytoplankton, benthic microalgae and macroalgae-dominated warm-temperate Australian lagoons. Mar Ecol Prog Ser 229:43-59

> Flindt M, Salomonsen J, Carrer M, Bocci M, Kamp-Nielsen L (1997) Loss, growth and transport dynamics of Chaetomorpha aerea and Ulva rigida in the Lagoon of Venice during an early summer field campaign. Ecol Model 102: 133-141

Flindt MR, Neto J, Amos CL, Pardal MA, Bergamasco A, Pedersen CB, Andersen FØ (2004) Plant bound nutrient transport: mass transport in estuaries and lagoons. In: Nielsen S, Banta G, Pedersen M (eds) Estuarine nutrient cycling: the influence of primary producers. Kluwer Academic Publishers, Dordrecht, p 93-128

- Fonseca MS, Cahalan JS (1992) A preliminary evaluation of wave attenuation by four species of seagrass. Estuar Coast Shelf Sci 35:565-576

> Fonseca MS, Fisher JS (1986) A comparison of canopy friction and sediment movement between four species of seagrass with reference to their ecology and restoration. Mar Ecol Prog Ser 29:15-22

> Friedrichs M, Graf G, Springer B (2000) Skimming flow induced over a simulated polychaete tube lawn at low population densities. Mar Ecol Prog Ser 192:219-228

Gambi MC, Nowell ARM, Jumars PA (1990) Flume observations on flow dynamics in Zostera marina (eelgrass) beds. Mar Ecol Prog Ser 61:159-169

Gremare A, Amouroux JM, Cauwet G, Charles F and others (2003) The effects of a strong winter storm on physical and biological variables at a shelf site in the Mediterranean. Oceanol Acta 26:407-419

Hansen JCR, Reidenbach MA (2012) Wave and tidally driven flows in eelgrass beds and their effect on sediment suspension. Mar Ecol Prog Ser 448:271-287

Hansen JW, Udy JW, Perry CJ, Dennison WC, Lomstein BA (2000) Effect of the seagrass Zostera capricorni on sediment microbial processes. Mar Ecol Prog Ser 199:83-96

Heiss WM, Smith AM, Probert PK (2000) Influence of the small intertidal seagrass Zostera novazelandica on linear water flow and sediment texture. N Z J Mar Freshw Res 34:689-694 
Houser CA, Nickling WG (2001) The factors influencing the abrasion efficiency of saltating grains on a clay-crusted playa. Earth Surf Process Landf 26:491-505

Huettel M, Webster IT (2001) Porewater flow in permeable sediments. In: Boudreau BP, Jorgensen BB (eds) The benthic boundary layer - transport processes and biogeochemistry. Oxford University Press, Oxford, p 144-170

- Huettel M, Ziebis M, Forster S, Luther GW (1998) Advection transport affecting metal and nutrient distributions and interfacial fluxes in permeable sediments. Geochim Cosmochim Acta 62:613-631

Kelly-Gerreyn BA, Hydes DJ, Waniek JJ (2005) Control of the diffusive boundary layer on benthic fluxes: a model study. Mar Ecol Prog Ser 292:61-74

Koch EW, Gust G (1999) Water flow in tide- and wavedominated beds of the seagrass Thalassia testudinum. Mar Ecol Prog Ser 184:63-72

> Kristensen E, Andersen FØ, Holmboe N, Holmer M, Thongtham N (2000) Carbon and nitrogen mineralization in sediments of the Bangrong mangrove area, Phuket, Thailand. Aquat Microb Ecol 22:199-213

Lawson SE (2008) Physical and biological controls on sediment and nutrient fluxes in a temperate lagoon, $\mathrm{PhD}$ dissertation, University of Virginia, Charlottesville, VA

Lawson SE, Wiberg PL, McGlathery KJ, Fugate DC (2007) Wind-driven sediment suspension controls light availability in a shallow coastal lagoon. Estuar Coasts 30: 102-112

Lorenzen C (1967) Determination of chlorophyll and phaeopigments: spectrophotometric equations. Limnol Oceanogr 12:343-346

Luhar M, Rominger J, Nepf H (2008) Interaction between flow, transport and vegetation spatial structure. Environ Fluid Mech 8:423-439

> Luhar M, Sylvain C, Infantes E, Fox S, Nepf H (2010) Wave induced velocities inside a model seagrass bed. J Geophys Res 115:C12005 doi:10.1029/2010JC006345

> Mariotti G, Fagherazzi S, Wiberg PL, McGlathery KJ, Carniello L, Defina A (2010) Influence of storm surges and sea level on shallow tidal basin erosive processes. J Geophys Res 115:C11012 doi:10.1029/2009JC005892

> McGlathery KJ, Anderson IC, Tyler AC (2001) Magnitude and variability of benthic and pelagic metabolism in a temperate coastal lagoon. Mar Ecol Prog Ser 216:1-15

McGlathery KJ, Sundbäck K, Anderson IC (2004) The importance of primary producers for benthic $\mathrm{N}$ and $\mathrm{P}$ cycling. In: Nielsen SL, Banta GM, Pedersen MF (eds) The influence of primary producers on estuarine nutrient cycling. Kluwer Academic, Dordrecht, p 231-261

McGlathery KJ, Sundbäck K, Anderson IC (2007) Eutrophication in shallow coastal bays and lagoons: the role of plants in the coastal filter. Mar Ecol Prog Ser 348:1-18

> McGlathery KJ, Reynolds LK, Cole LW, Orth RJ, Marion SR, Schwarzschild A (2012) Recovery trajectories during state change from bare sediment to eelgrass dominance. Mar Ecol Prog Ser 448:209-221

> Moore KA (2004) Influence of seagrasses on water quality in shallow regions of the lower Chesapeake Bay. J Coast Res 45:162-178

Morin J, Morse JW (1999) Ammonium release from resuspended sediments in the Laguna Madre estuary. Mar Chem 65:97-110

$>$ Nepf HM (1999) Drag, turbulence, and diffusion in flow through emergent vegetation. Water Resour Res 35: 479-489
Orth RJ, Moore KA (1986) Seasonal and year-to-year variations in the growth of Zostera marina L. (eelgrass) in the lower Chesapeake Bay. Aquat Bot 24:335-341

Orth RJ, Luckenbach ML, Marion SR, Moore KA, Wilcox DJ (2006) Seagrass recovery in the Delmarva Coastal Bays, USA. Aquat Bot 84:26-36

> Orth RJ, Moore KA, Marion SR, Wilcox DJ, Parrish DB (2012) Seed addition facilitates eelgrass recovery in a coastal bay system. Mar Ecol Prog Ser 448:177-195

> Peterson CH, Luettich RA, Micheli F, Skilleter GA (2004) Attenuation of water flow inside seagrass canopies of differing structure. Mar Ecol Prog Ser 268:81-92

Porter ET, Cornwell JC, Sanford LP (2004a) Effect of oysters Crassostrea virginica and bottom shear velocity on benthic-pelagic coupling and estuarine water quality. Mar Ecol Prog Ser 271:61-75

> Porter ET, Sanford LP, Gust G, Porter FS (2004b) Combined water-column mixing and benthic boundary-layer flow in mesocosms: key for realistic benthic-pelagic coupling studies. Mar Ecol Prog Ser 271:43-60

> Romano C, Widdows J, Brinsley MD, Staff FJ (2003) Impact of Enteromorpha intestinalis mats on near-bed currents and sediment dynamics: flume studies. Mar Ecol Prog Ser 256:63-74

Sadeque MAF, Rajartnam N, Loewen MR (2008) Flow around cylinders in open channels. J Eng Mech 134:60-70

> Sand-Jensen K, Borum J (1991) Interactions among phytoplankton, periphyton, and macrophytes in temperate freshwaters and estuaries. Aquat Bot 41:137-175

Sanford LP, Maa JPY (2001) A unified erosion formulation for fine sediments. Mar Geol 179:9-23

Sfriso A, Marcomini A (1997) Macrophyte production in a shallow coastal lagoon 1. Coupling with chemicophysical parameters and nutrient concentrations in waters. Mar Environ Res 44:351-375

Sfriso A, Facca C, Marcomini A (2005) Sedimentation rates and erosion processes in the lagoon of Venice. Environ Int 31:983-992

Stevens AW, Wheatcroft RA, Wiberg PL (2007) Seabed properties and sediment erodibility along the western Adriatic margin, Italy. Cont Shelf Res 27:400-416

Stumpf RP, Frayer ML, Durako MJ, Brock JC (1999) Variations in water clarity and bottom albedo in Florida Bay from 1985 to 1997. Estuaries 22:431-444

> Sundbäck K, Miles A, Goransson E (2000) Nitrogen fluxes, denitrification and the role of microphytobenthos in microtidal shallow-water sediments: an annual study. Mar Ecol Prog Ser 200:59-76

Tengberg A, Stahl H, Gust G, Muller V, Arning U, Andersson $\mathrm{H}$, Hall POJ (2004) Intercalibration of benthic flux chambers I. Accuracy of flux measurements and influence of chamber hydrodynamics. Prog Oceanogr 60: $1-28$

Thompson CEL, Amos CL (2002) The impact of mobile disarticulated shells of Cerastoderma edulis on the abrasion of a cohesive substrate. Estuaries 25:204-214

Thompson CEL, Amos CL (2004) Effect of sand movement on a cohesive substrate. J Hydraul Eng 130:1123-1125

Thomsen L, Gust G (2000) Sediment stability and characteristics of resuspended aggregates of the western European continental margin. Deep-Sea Res I 47: 1881-1897

Thomsen MS, McGlathery KJ (2005) Facilitation of macroalgae by the sedimentary tube forming polychaete Diopatra cuprea. Estuar Coast Shelf Sci 62:63-73 
Thomsen MS, McGlathery KJ, Tyler AC (2006) Macroalgal distribution patterns in a shallow, soft-bottom lagoon, with emphasis on the nonnative Gracilaria vermiculophylla and Codium fragile. Estuar Coasts 29:470-478

Thybo-Christesen M, Rasmussen MB, Blackburn TH (1993) Nutrient fluxes and growth of Cladophora sericea in a shallow Danish Bay. Mar Ecol Prog Ser 100:273-281

Traykovski P, Wiberg PL, Geyer WR (2007) Observations and modeling of wave-supported sediment gravity flows on the Po prodelta and comparison to prior observations from the Eel shelf. Cont Shelf Res 27:375-399

Tyler AC, McGlathery KJ, Anderson IC (2001) Macroalgal mediation of dissolved organic nitrogen fluxes in a temperate coastal lagoon. Estuar Coast Shelf Sci 53:155-168

> Viaroli P, Bartoli M, Bondavalli C, Christian RR, Giordani G, Naldi M (1996) Macrophyte communities and their impact on benthic fluxes of oxygen, sulphide and nutrients in shallow eutrophic environments. Hydrobiologia 329:105-119

> Ward LG, Kemp WM, Boynton WR (1984) The influence of

Submitted: July 5, 2011; Accepted: December 28, 2011 waves and seagrass communities on suspended particulates in an estuarine embayment. Mar Geol 59:85-103

Wiberg PL, Law BA, Wheatcroft RA, Milligan TG, Hill PS (in press) Seasonal variations in erodibility and sediment transport potential. Cont Shelf Res

Widdows J, Lucas JS, Brinsley MD, Salkeld PN, Staff FJ (2002) Investigation of the effects of current velocity on mussel feeding and mussel bed stability using an annular flume. Helgol Mar Res 56:3-12

Yamamuro M, Hiratsuka JI, Ishitobi Y, Hosokawa S, Nakamura Y (2006) Ecosystem shift resulting from loss of eelgrass and other submerged aquatic vegetation in two estuarine lagoons, Lake Nakaumi and Lake Shinji, Japan. J Oceanogr 62:551-558

> Zheng LY, Chen CS, Zhang F (2004) Development of water quality model in the Satilla River Estuary, Georgia. Ecol Model 178:457-482

Ziervogel K, Bohling B (2003) Sedimentological parameters and erosion behaviour of submarine coastal sediments in the south-western Baltic Sea. Geo-Mar Lett 23:43-52

Proofs received from author(s): February 3, 2012 